\title{
The Right to Health and Access to Drug from the Viewpoints of International Humanitarian Law and Human Rights, and Iran Provisions Morteza Gholi-Shafiei $^{1} \mathbb{D}$, Leila Raeisi-Dezki ${ }^{2} \mathbb{D}$, Mahmoud Jalali-Karveh $^{3}$
}

Date of submission: 28 Apr. 2018, Date of acceptance: 22 Jul. 2019

\section{Review Article}

Abstract

INTRODUCTION: The right to access to drug is not specified as an independent right in the international documents; and has been considered in the area of health, as one of the equipment of being healthy. Right to physical and mental health has been described and recognized absolutely as a foundational right in the international humanitarian rights documents. In this research, we studied the right to health and access to drug from the viewpoints of international humanitarian law and human rights.

METHODS: In this descriptive-analytic research, some of international documents about human rights and international humanitarian law, as well as some provisions of Iran and some related cases were studied using library research tools.

FINDINGS: The importance of attention to right access to drug as a fundamental human right was emphasized in international and Iran documents.

CONCLUSION: As the right access to drug is considered as a fundamental human right, it seems that a specific international covenant should be codified on this issue by the United Nation and other international competent organizations.

Keywords: Right to Health; Right to Access to Drug; International Humanitarian Rights

How to cite this article: Gholi-Shafiei M, Raeisi-Dezki L, Jalali-Karveh M. The Right to Health and Access to Drug from the Viewpoints of International Humanitarian Law and Human Rights and, Iran Provisions. Sci J Rescue Relief 2019; 11(2): 138-44.

\section{Introduction}

$\mathrm{T}$ The right to health is one of the fundamental human rights. This right to life is considered as one of the first undeniable human rights. Speaking about other human rights makes no sense while ignoring the right to life. The right to access to drug is also a right to health necessity, in other words it refers to the right of every human being to benefit from the highest degree of physical and mental health. Items such as the right to safe drinking water, adequate and complete food, the enjoyment of a clean and healthy environment, and the enjoyment of public health and primary care and health services, along with the right to access medicines are considered as the highest achievable standard of health rights (1).

The above items as part of the humanitarian and human rights, which seek to prevent excessive violence in wars, are two complementary branches of international law. In addition, given the human and philosophical principles, historical interaction, and their common purpose of protecting human rights, they are practically approaching each other, so that the interplay of human rights and humanitarian law can be stated to double the effect of protecting human rights.

The main question in this study was whether international documents have regarded the right to health as a major and important issue or as a minor one? Thus, the present study addresses

\footnotetext{
1- PhD Student, International Law, Department of Law, School of Humanities and Law, Isfahan (Khorasgan) Branch, Islamic Azad University, Isfahan, Iran

2- PhD, Department of Law, School of Humanities and Law, Isfahan (Khorasgan) Branch, Islamic Azad University, Isfahan, Iran

3- PhD, Department of Law, School of Administrative Sciences and Economics, University of Isfahan, Isfahan, Iran

Correspondence to: Leila Raeisi-Dezki, Email: raisi.leila@gmail.com
} 
some of the important international documents and as an example, the national Iranian documents and regulations on the subject.

\section{Methods}

This was a descriptive-analytical study performed using the library tool. The international documents, particularly the human rights and humanitarian law documents, Iranian laws, and associated documents were studied to answer the main question and explain the hypothesis considered. Content description and analysis in the field of law involves interpretations of the existing laws and conventions and various understandings of laws and conventions are usually expressed in the framework of articles. The texts have also been used with such an attitude in the present study, in addition to exploiting new technologies, particularly computer programs and scanning of documents from different libraries.

\section{Findings}

The Charter of the United Nations is one of the documents considered to be the mother of other international documents. An article of this charter which may in some way be regarded as a right of access to health is Article 55 of this charter. Paragraph (a) of this article obliges the United Nations to promote higher standards of living and paragraph (b) of this article obliges the organization seek solutions to international health issues. Certainly, one of the ways to promote higher standards of living is to provide individuals with access to drugs, which has been considered as an international constitution by the UN Charter.

The World Health Organization (WHO) is the most relevant international organization in the health field. The statute of this organization begins with the following statements: The states parties to the statute declare that in implementing the UN charter, which seeks for the essential principles of happiness, harmonious relations, and security of all peoples, health is a concept that embraces physical and mental health and social well-being, and does not include only disease or infirmity. The introduction of the WHO statute also declares that: The enjoyment of the highest attainable level of standard of health is one of the basic rights of every human being regardless of their racial, religious, political, economic, or social differences and conditions (2). The first part of the WHO statute, which includes Article 1 of the statute, entitled "Goal": The goal of the World Health Organization (hereinafter referred to as the Organization) is to achieve the highest possible level of health for all individuals (3).

The Universal Declaration of Human Rights (UDHR), adopted by the UN General Assembly on December 10,1948, is the result of the experiences from World War II. UDHR is a document that has addressed fundamental human rights for the first time. This document has been approved by representatives of different countries with different legal and cultural systems and has been confirmed by UN General Assembly resolution 217 A. The document, which has been translated into more than 500 languages so far, is regarded as a "milestone" in the history of human rights. Article 3 of the declaration states that: "Every individual has the right to life, liberty, and security". Paragraph 1 of Article 25 of the declaration states: "Everyone has the right to provide a standard living, health, and well-being for himself and his family, in particular in terms of food, clothing, housing, medical care, and social services ...". As it is clear, this document does not explicitly refer to the right to health and the right of access to medication, however the right to life has been pointed out in Article 3 of this Declaration.

The right to health has been explicitly and fully pointed out in Article 12, paragraph 1, of the International Covenant on Economic, Social and Cultural Rights (ICESCR); this paragraph states that: "Sates parties to the present covenant recognize the right of every individual to the enjoyment of the highest attainable standard of physical and mental health". To exercise this right, paragraph 2 of this article clarifies in four paragraphs the need to take measures such as reducing child mortality at birth and afterwards and their healthy development, improving environmental health, preventing and curing epidemic, indigenous, occupational, and other diseases, fighting against these diseases, and establishing the proper conditions for medical assistance for the public in case of diseases. Concerning the availability of research results and innovations, which would naturally include pharmaceutical innovations, Section 3 of paragraph 1 of Article 15 of ICESCR states: "States should be obliged to provide appropriate ground for the availability of the scientific research results and information on new products and ideas and to exchange scientific findings" (4). 
Article 5 of the International Convention on the Elimination of All Forms of Racial Discrimination, referring to the obligations of the states under Article 2 of the convention, has obliged the states to prohibit and eliminate all forms of racial discrimination. This article also obliges the states to grant without legal discrimination, including the rights set forth in Section 4 of paragraph (a) of this article. The rights set forth in Section 4 of this paragraph, which are considered to be among the economic, social, and cultural rights, have been specifically worded as follows: "Rights to public health, medical care, social security, and social services".

Article 12 of the Convention on the Elimination of All Forms of Discrimination against Women, taking into account the right to health, points out the consensus of all states parties on taking all appropriate measures to ensure access to health care services for men and women on an equal footing. Paragraph 1 of this article states: "States parties shall adopt measures to eliminate discrimination against women in the field of medical care on the basis of equality between men and women in access to health care services including family relations". Article 12, paragraph 2, of this convention addresses the provision of measures for access to services for women during pregnancy and after childbirth, with access to drugs having a particular place in this issue.

The Agreement on Trade-Related Aspects of Intellectual Property Rights (TRIPS): One of the agreements in incorporated to the World Trade Organization (WTO) statute is the agreement on the trade-related aspects of intellectual property rights. Some believe that the provisions of this agreement have caused conflicts with the right to health and access to medicines by supporting the intellectual property rights of the drug inventors. However, the advocates of the right to drug innovation declare that there is no conflict, and if there is one, it is an apparent and international system conflict. The intellectual property rights are designed in such a way to address human rights concerns and respond to conflicts. Pressure by human rights groups made the issue of drug be one of the main topics on the agenda of the first WTO meeting of ministers since the formation of this organization, which also become one of the most controversial issues in this round of negotiations (5).
While protection of intellectual property rights is some kind of protection of a human right called the right to property, when a fundamental right such as the right to health is at stake, other rights may be violated in some cases. In fact, if the human's right to health is considered as the "ultimate value" and the goal of the International Humanitarian Law system, the international law should regard intellectual property as a "method" that is merely a method, rather than an issue, and therefore "value" would be prioritized in case of a conflict between these two rights (6). Paragraph 2 of Intellectual property and Human Rights, Sub Commission on Human Rights resolution 2000/7, United Nation High Commissioner for Human Rights clearly states that the implementation of the TRIPS Agreement has not generally reflected the fundamental and indivisible nature of human rights, including the right of individuals to benefit from scientific advancement and its consequences, the right of individuals to health, and the right to self-determination. This paragraph stipulates that "there are clear conflicts between the intellectual property rights system set forth in the TRIPS Agreement on the one hand and the International Humanitarian Law system on the other". The third paragraph emphasizes the "primacy of human rights obligations on economic policies and agreements" (7). The Sub Commission on Human Rights resolution 2000/7 is a pivotal point in the international plan for the intellectual property rights and human rights. This resolution recognizes Article 28 of UDHR as a platform for moving forward and as a window to look at the issue and considers the basis of its action to be protecting ICESCR (8). In 2001, the committee reaffirmed, in accordance with Resolution 21, the primacy of human rights obligations over economic agreements and policies under paragraph 3 of this resolution (9). Nevertheless, issues such as acquired immunodeficiency syndrome (AIDS) disease in South Africa and other issues have persuaded WTO members to resolve the conflict in the TRIPS provisions and access to drug. Measures to amend the TRIPS agreement in 2003, albeit being considered a step forward, have not yet been able to resolve the conflicts. The August 30, 2003 Doha Declaration showed high flexibility in WTO decision-making procedure, indicating that WTO members would enforce formal regulations 
flexibly in case of conflicts between the organization's rights and human rights (10).

The ultimate goal of access to medicines is the well-being of patients, besides, in the economic dimension (intellectual property rights), continuing industrial productivity is naturally considered through the creation of innovation in the pharmaceutical field. Therefore, through the contribution of other stakeholders, particularly governments and civil society, it can be claimed that there is no conflict between human rights and intellectual property rights, since they are two different areas with different goals. The right to health is a fundamental right related to the dignity of individuals, while the intellectual property rights are an economic instrument for achieving specific goals. What is certain is the need for all actors to publicly work together to achieve health and to fulfill the right to health (11).

Right to Health and Medicine from a Human Rights Perspective: Short-term and long-term wars with devastating effects, human casualties, and various catastrophes have been unavoidable throughout human history. Although no regulations have been put in place to ban war, rules have been established on war-related issues, known as "law of war", and taught in academic centers with the same title. The observance and acceptance of these regulations by all governments have been emphasized in such a way that they can be said to have become customary rules. The term "International Humanitarian Law (IHL)", which has a broader meaning and encompasses all international rules concerning military individuals, civilians, and injured and healthy individuals in international conflicts, has a relatively new origin, and in four 1949 Geneva conventions, the 1977 Protocols, and the 2005 Accession Protocol [Protocol I (1977) relating to the Protection of Victims of International Armed Conflicts, Protocol II (1977) relating to the Protection of Victims of Non-International Armed Conflicts], these is not such a term. Regarding the international humanitarian law, if there is little doubt about their connection to the Jus Cogens of international law, there is no doubt that the fundamental principles of humanitarian law, which are in fact the same Article 3 common to the four Geneva conventions, are part of the Jus Cogens of international law (12). The following statement has been made regarding the historical confluence of international humanitarian law and the law of war: the confluence of these two legal concepts has begun with the acceptance of the 1977 amendment protocol to the Geneva Conventions. Although human rights-based provisions in The Hague Conventions (such as the protection of special prisoners of war and citizens of the occupied countries) are found, however, the 1977 Protocol concerning the protection of victims of international and domestic conflicts, not only deals with the issues of the Hague and Geneva conventions, but is also about all important human rights (13). Given this attitude, the issue of safety and health has been debated as a human right, and regarding the relationship between the two categories of rights in conflicts it has been declared that: "In case of war, the link between health and human security allows for analyzing the direct and indirect effects of conflicts" (14).

Article 12 of the Second Geneva Convention and the second paragraph of Article 10 of the First Additional Protocol and the second paragraph of Article 7 of the Second Additional Protocol to the Geneva Conventions shall mean that any injury to the life of the injured, the patients, the shipwrecked passengers, or any form of violent behavior with them is forbidden. Since the care for the injured and patients requires access to drug and medical supplies, the above provisions may also extend to the right to access drug. Given the importance of this issue, the International Law Commission has also put this issue on the agenda under the title "Supporting individuals in critical events" and has asked the Red Cross and Red Crescent societies to respond to their questions (15). According to Rabus, the regulations associated with the patients and the injured also apply to civilians who are exposed to injuries or illnesses and the need to medical assistance, including access to medication, is a key criterion in the application of the terms "injured" and "patient" (16). Concerning the need to provide medical equipment and drug to patients and the injured, Article 1 of the Geneva Convention states that: relief facilities, including drug distribution, may be seized and detained only if medical care for the injured and patients is guaranteed (17). Regarding the prohibition of the seizure of ships carrying medical supplies and medicines and other medical equipment, it is said that the ships carrying material exclusively for the treatment of the injured and patients or for the prevention of 
diseases if their cargo characteristics are confirmed, cannot be attacked or seized (18). Concerning the immunity of vessels carrying relief supplies to civilian populations in territories under control, paragraph 2 of Article 70 of the First Additional Protocol, states: vessels that carry relief supplies with the consent of the parties involved to civilian populations in territories under the control of another party other than that of the occupied territory shall also be protected (18). About the type of the goods transported by these vessels, Von Heinegg declares: "The materials and goods on board these vessels must, however, be purely consistent with the human rights goals (19) and should not be regarded as an unfriendly or intrusive measure, in which the international organizations such as the Red Cross play an essential role (20).

Right to Health and Access to Drug in Iranian Provisions: In November 2009, Iran's Public Health Insurance Law was passed by the Islamic Consultative Assembly, which subsequently led to the establishment of the health insurance organization in the country with the goal of providing health and medical care in the event of incidents as a form of public insurance for government employees and optional insurers. Contracting with all state hospitals and public health centers, as well as some hospitals, clinics, laboratories, pharmacies and doctors in the private sector, this organization provides services to the insured. In this way, the insured pay only part of their costs as franchisees when referring to the insurance contracting centers and the contracting centers receive the rest of the expenses from the Iran Health Insurance Organization. In accordance with Article 5 of the Fifth Five-Year National Development Plan, different parts of the Health Insurance Organization and its insurance funds were incorporated, and the Iran Health Insurance Organization was founded on the basis of a charter dated August 12, 2012 and accordingly, on September 22, 2012, the Iran Health Insurance Organization officially began its activity and was tasked to concentrate all the health insurance affairs in the organization through integration of the medical insurance sector of funds subject to Article 5 of the Act on Civil Service Management and Article 5 of the Act on National Computing while compliance with the provisions of Article 38 of the Fifth Five-Year National Development Plan.
As stated previously, the constitutions and common rules of most countries have highlighted the right to health. For example, the cases referring to Iranian regulations in this regard include: Article 29 and paragraph 1 of Article 43 of the Constitution of the Islamic Republic of Iran addresses the social security and public health matters. Paragraph 12 of Article 3 also somehow refers to a right to health instruments, and Articles 20 and 21 do so. The Fourth Five-Year Economic, Social and Cultural Development Plan is dedicated to promoting health and improving the quality of life (QOL). The right to health has been addressed in the 20-Year National Vision of the Islamic Republic of Iran, and it is said that one of the goals of a democratic economy is to provide a longer and healthier life for the people. In addition, Articles 32-40 of the Fifth Development Plan also addresses the issue of health and measures to maintain and protect it. The 20-Year National Vision document, while describing the characteristics of a healthy Iranian society as a society benefiting from health, welfare, food security, social security, equal opportunities, suitable income distribution, strong family institution, lack of poverty, corruption, and discrimination, and ideal environment, emphasizes the various socio-economic dimensions leading to health.

Given that the Sixth Development Plan is the Iran's newest five-year plan adopted on March 14, 2017 by the Islamic Consultative Assembly, this section deals with the health-related provisions of this law. Section 3 of Paragraph 43 introduces the general policies of the Sixth Development Plan for sustainable financing for the health sector and the quantitative and qualitative development of health insurances, besides, Section 4 of this paragraph recommends a policy as enhancing the quality and safety of comprehensive and integrated health care services in the form of the healthcare and treatment network in accordance with the referral and grading system (21).

According to Article 72 of the Sixth Development Plan Act, a health trustee has been designated and it has been stated in paragraph A that: "The health system, including health insurance, supervision including executive policymaking, strategic planning, evaluation, accreditation, and supervision is concentrated at the Ministry of Health and Medical Education". 
Therefore, the Ministry of Health and Medical Education has been appointed as the trustee of health affairs in Iranian law.

\section{Discussion and Conclusion}

With regard to the above-mentioned human rights issues, the right to health and access to medicine from the perspective of human rights and humanitarian law are two issues arising from observance of the human health and protection from damages threatening human rights. Regarding the first issue, i.e. observance of hygiene which is one of the essentials of health, the financial and political support of organizations such as WHO and coordination of WTO and the World Intellectual Property Organization (WIPO) can lead to greater human health. Concerning fighting against the epidemic and hazardous illnesses such as AIDS that widely threaten human lives, the international organizations are capable of tackling and eradicating such diseases. Moreover, about the subject of humanitarian law, it is also necessary to strengthen bodies such as the International Committee of the Red Cross (ICRC), which acts as a protector of international humanitarian law and operates under the four Geneva Conventions adopted in 1949 and the two Additional Protocols adopted in 1977. These documents enable ICRC to carry out activities such as providing relief to the injured, the sick, and the shipwrecked military individuals, visiting prisoners of war, restoring relationships between family members separated by conflict, assisting civilians, and ensuring proper treatment with people supported by the international humanitarian law. ICRC operates in 80 countries, and the ICRC's network of representative offices is regularly updated to coordinate evolutions in the armed conflicts and other forms of violence. The ICRC center is located in Geneva, Switzerland. As noted above, human rights and humanitarian law, which seeks to prevent excessive violence in wars by setting forth regulations, are two complementary branches of international law given their common human and philosophical principles, historic interaction, and goal of protecting human rights. Today, not only have wars not declined, but unfortunately modern wars happen more and more with more modern software and hardware weaponry with more tragic impact.

Given the material presented, it can be concluded that the human right to health and access to drug is a fundamental human right as health is one of the essentials of the right to life. As stated above, the right to health is a right that has been emphasized in most human rights documents. The human rights documents have obligations and commitments specifically aimed at governments. Among the commitments of governments regarding the right to health and access to medicine are commitment to respect, support, and implementation. Commitment to respect requires that governments avoid direct or indirect interference in the enjoyment of the right to health. The commitment to support requires the governments to protect the right to health against third-party interference and disturbances, and ultimately the commitment to implementation encompasses a wide range of legal, judicial, financial, and other measures to exercise and advance the right to health. In line with the recent commitment, countries have been trying to adjust or amend their domestic regulations in line with the international regulations. This should not, however, prevent governments from taking immediate action to access health services, establish hospitals and clinics, and access medicines at affordable prices, with healthy food and water in emergency cases. In spite of the human desire to avoid war and armed conflicts, such a wish has not been fulfilled in history, so paying attention to humanitarian regulations and developing and adhering to regulations in accordance with wars and modern hardware and software weaponry is a matter of great concern requiring increasing attention of national and international authorities. Therefore, it is expected that an international treaty on the subject of the necessity of attention to health and access to drug and a treaty on humanitarian law be adopted to take a step towards approaching the concept of justice in line with the interests of the international community. Fulfillment of this expectation requires careful and scientific investigations and efforts of human rights researchers and sympathizers as well as the increasing attention of authorities such as the Red Cross and the Red Crescent Society, in particular taking into account the fact that modern wars with modern software and hardware weapons are threatening human life.

\section{Acknowledgments}

The authors would like to appreciate all individuals who contributed to this study. 


\section{Conflict of Interests}

Authors have no conflict of interests.

\section{References}

1. Zamani SG. Therapeutic cloning and the right to health in international humanitarian law. Law \& Politics Research Journal 2006; 8(19): 25-40. [In Persian].

2. Constitution of the world health organization https://www.who.int/governance/eb/who_constituti on_en.pdf

3. The objective of the World Health Organization "hereinafter called the Organization", 2020. Ibid: chapter i-objective Article 1.

4. International Covenant on Economic, Social, and Cultural Rights, 2020. https://www.ohchr.org/en/ professionalinterest/pages/cescr.aspx

5. Sadeghi M. The Protection of pharmaceutical innovation, and accession to the World Trade Organization. Tehran, Iran: Mizan Publications; 2008. p. 14. [In Persian].

6. Ghari Seyed Fatemi SM. Human rights in the contemporary world: An Introduction to Theoretical Topics: Concepts, Principles, Territory and Resources. Tehran, Iran: Shahr Danesh Publications; 2011. p. 54. [In Persian].

7. Habibi Majandeh M. Intellectual property rights and human rights, interactions and conflicts. Qom, Iran: Mofid University Publications; 2015. p. 38. [In Persian].

8. Ibid.

9. Hester Mir H. Human Rights and the World Trade Organization, patents and access to medicines. Trans. Hosseini Akbarnejad H, Hosseini Akbarnejad H. Tehran, Iran: Shahre Danesh Publications; 2011. p. 449. [In Persian].

10. Lenk C, Andorno R, Hoppe N. Ethics and law of intellectual property: current problems in politics, science and technology. Trans. Abiri A. Tehran, Iran: Mizan Publications; 2014. p. 102, 103. [In Persian].

11. Momtaz J, Ranjbarian AH. Human rights (Internal armed conflicts). Tehran, Iran: Mizan Publications; 2007. p. 44. [In Persian].

12. Wikipedia. International humanitarian law [Online]. [cited 2017]; Available from: URL: https://en.wikipedia.org/wiki/International_humanit arian_law\#cite_ref-61

13. Krause K. The key to a powerful agenda, if properly delimited. Security Dialogue 2004; 35(3): 367-8.

14. International Law Commission. Draft articles on the responsibility of international organizations [Online]. [cited 2011]; Available from: URL: https://legal.un.org/ilc/texts/instruments/english/dra $\mathrm{ft}$ articles/9_11_2011.pdf

15. ILC, $63^{\text {rd }}$ Session, Rep. A/RES/63/123, 2009. Available:https://library.un.org/sites/library.un.org/ files/itp/a63-parti_0.pdf

16. Rabus W, Protecting the Wounded, the Patients and the Broken Ship (Human rights in armed conflict), translation by Saed N, 1th ed. Tehran: Institute of Legal Studies and Research of Shahre Danesh, 2008, p. 390.

17. Dinstein Y, The Conduct of Hostilities under the Law of International Armed Conflict, Cambridge University Press, UK, 2005, P. 168

18. ICRC. Protocol Additional to the Geneva Conventions of 12 August 1949, and relating to the Protection of Victims of International Armed Conflicts cited 1977;Availablehttps://ihldatabases.icrc.org /applic/ ihl/ihl.nsf/ Treaty.xsp? action $=$ openDocument\&documentId=D9E6B6264 D7723C3C12563CD002D6CE4

19. Von Heinegg WH. The law of armed conflict at sea. In: Fleck D, Bothe M, Editors. The handbook of international humanitarian law. Oxford, UK: Oxford University Press; 2008. p. 558.

20. Grasser HP. Protection of the civilian population. In: Fleck D, Bothe M, Editors. The handbook of international humanitarian law. Oxford, UK: Oxford University Press; 2008. p. 243.

21. Clause 43-3 of Sixth Development Plan Policy available at /www.doe.ir/portal/file/?656944/ 